\title{
Hydration and water holding properties of cross-linked lignite humic acids
}

\author{
Zdeněk Cihlář ${ }^{a}$, Lucy Vojtová ${ }^{a}$, Pellegrino Conte ${ }^{b}$, Saqib Nasir ${ }^{c}$, Jiří Kučerík ${ }^{\text {d,* }}$ \\ a CEITEC - Central European Institute of Technology, Brno University of Technology Technická 3058/10, 61600 Brno, Czech Republic \\ b Dipartimento di Scienze Agrarie e Forestali, Università degli Studi di Palermo, v.le delle Scienze edificio 4, 90128, Palermo, Italy \\ c Pakistan Council of Scientific E' Industrial Research, Ministry of Science E Technology, Lahore-54600, Pakistan \\ d University of Koblenz-Landau, Institute for Environmental Sciences, Soil and Environmental Chemistry, Fortstr. 7, Landau 76829, Germany
}

\section{A R T I C L E I N F O}

\section{Article history:}

Received 16 July 2013

Received in revised form 2 April 2014

Accepted 14 April 2014

Available online $\mathrm{xxxx}$

\section{Keywords:}

lignite humic acids

cross-linking

hydration

DSC

NMR relaxometry

water molecule bridges

\begin{abstract}
A B S T R A C T
Lignite and lignite humic acids, which are used as soil amendments sometimes, are supposed to improve soil properties such as water holding capacity. The structure of those materials is composed of various organic molecules stabilized mostly by weak interactions. Therefore, excess of water causes only partial swelling, but most of the physical structure is destabilized. This accelerates the desiccation and hampers their application as natural hydrogel-like substances. In order to stabilize the structure of lignite humic acids and improve the water holding capacity, we applied formaldehyde cross-linking procedure based on covalent coupling of aromatic humic acids moieties. By combining the ${ }^{1} \mathrm{H}$ NMR relaxometry and methods of thermal analysis, the kinetics and degree of hydration, water distribution and moisture uptake were investigated. It was found that cross-linking induced a reduction in moisture sorption capacity at low relative humidity and an increase at higher relative humidity, which was attributed to the separation of functional groups and decreasing of structural compactness after crosslinking. As a result, the cross-linked humic acids, exhibited faster water uptake and approximately three-fold higher water holding capacity in comparison with the parental sample. The distribution of relaxation times of water protons in swollen humic acids revealed the unification of pore size distribution upon cross-linking. Although the improved hydration of cross-linked lignite humic acids already resembles the hydration of some hydrophilic polymers, the water holding capacity is still below the capacity of classical hydrogels. Nevertheless, the low price of lignite, sorption properties and its overall positive affect on soil quality and productivity give a promise in application of this material both in agriculture and remediation technologies.
\end{abstract}

(C) 2014 Elsevier B.V. All rights reserved.

\section{Introduction}

Intensive agricultural practices together with needs to meet the increasing global food demands are responsible for the desertification processes occurring in the hottest and Southernmost world countries (Kefi et al., 2007). In order to keep soil fertility, both organic and inorganic fertilization practices are traditionally applied. Nowadays, new organic amendments are under consideration. In fact, they are supposed to increase both soil fertility, soil physicochemical characteristics and carbon sequestration, thereby favoring crop productions and preventing emissions of greenhouse gases to the atmosphere (Lehmann and Joseph, 2009). Last decade, among the most studied organic amendments belong chars (or biochars)(Madari et al., 2012), which are carbon-rich products obtained through carbonization of biomasses as it occurs, for example, during pyrolysis and pyrogasification ((Cimò et al., 2014; Conte et al., 2013b; De Pasquale et al., 2012; Knicker, 2010; Knicker et al., 2013). However, also other "cheap and available" carbon-

\footnotetext{
* Corresponding author. Tel.: +496341280 31582; fax: +49634128031576.

E-mail address: kucerik@uni-landau.de (J. Kučerík).
}

containing materials deserve special attention. One of the most prominent is lignite, which unlike charcoal, has lower structural integrity, contains high amounts of volatile components and has relatively low carbon/oxygen ratio. The latter is caused by the presence of original, not coalified wooden rests, high content of mineral inclusions and relatively high content of humic substances (HS) (Honek et al., 2009).

Humic substances are versatile materials caused mainly by their polyfunctionality (Nasir et al., 2011b). The functions include a wide range of interactions (Sutton and Sposito, 2005), biological activity (David et al., 2014; Jindo et al., 2012), water holding capacity (Stevenson, 1994). However, the positive effect of humic substancesbased amendments in environmental and agricultural applications can be easily reversed. For example, the S. cerevisiae D7 tests showed the positive antimutagenic effect of native sodium and potassium salts. However, a short heating of those samples induced a negative effect (Marova et al., 2011). Thus, the humic acids preparation and modification requires a special attention.

Numerous studies have shown that humic substances are capable of altering both the chemical and the physical speciation of the ecotoxicants and affect their bioavailability and toxicity (Simpson and Hatcher, 2004). 
The potential utilization of humic substances originating either from lignite or from other sources in agriculture, in environmental technologies and industry has been reported several times (Bakajova et al., 2011; Ctvrtnickova et al., 2011; Nasir, 2011; Nasir et al., 2011a; von Wandruszka, 2000). Using nitric acid and/or hydrogen peroxide (Kucerik et al., 2003), air (Kučerík et al., 2008) or air oxidation under elevated temperature (Calemma et al., 1994), in lignite, the content of humic acids can be significantly increased. However, the unpredictable behavior and structural heterogeneity are (among others) factors reducing the wider applications of humic substances. Their chemical modification is one of the possibilities, how to enhance and control their reactivity, thermal and chemical resistance, sorption properties and solubility (Ryabova and Mustafina, 2003). In this case, the procedures known from polymer science are frequently applied. For example, modification of humic acids with formaldehyde decreases the solubility, increases sorption capacity for calcium cations, whereas the average ionization constant remains unchanged. Formaldehyde crosslinking causes also redistribution of the electron density in the condensed HA system, thereby enhancing the acid properties of weak acid groups and thus increasing the static exchange capacity (Ryabova and Mustafina, 2003). Another promising direction for controlled cross-linking of humic substances is curing of humic phenol-formaldehyde segments, which enhances their detoxifying ability towards heavy metals (Kovalenko et al., 2006). Using those reactions, additional phenolic and quinonoid moieties can be incorporated into humic backbone (Perminova et al., 2005).

Because the modification of humic substances represents additional costs, it has to improve the targeted properties significantly. One of the most prominent properties of humic substances is the water retention capacity, which is connected with their partial hydrophilicity and porous character (Jaeger et al., 2010). At low water content, the water molecule bridges (WaMB) connect and stabilize the segments of soil organic matter (Aquino et al., 2011; Schaumann and Bertmer, 2008; Schaumann and LeBoeuf, 2005). Increasing water content improves sorption capacity of organic matter towards the non-polar compounds (Borisover, 2013; Borisover and Graber, 2004), which underlines the importance of non-covalent polar links in stabilization of soil organic matter supramolecular structure. Excess of water content breaks those interactions (Kucerik et al., 2012) thereby decreasing the structural compactness. This might cause problems in humic-substances based amendments due to their fast desiccation and uncontrolled water release. From the polymer chemistry point of view, this situation can be improved by introduction of covalent bindings, i.e. cross-linking connecting loosely bound molecules.

The cross-linking plays very likely also a role in the humification of natural organic matter and the diagenesis of organic geopolymers (Grasset and Ambles, 1998; Grasset et al., 2002; Pignatello, 2012). This structural stabilization may be important to the ecological function of humic substances, but this issue has been poorly investigated yet (Schneckenburger et al., 2012). Therefore, the investigation of properties of cross-linked humic substances is beneficial both for understanding of their function and their application potential.

The objective of this study was to test the chemical and physicochemical properties of pre-oxidized and formaldehyde cross-linked humic acids obtained from South Moravian lignite. Further, the detail study on the water holding capacity, hydration mechanisms and water distribution in parental and cross-linked humic acids is presented. Obtained information has the relevance in fundamental research, because it brings new information about the hydration mechanisms of humic acids as well as in technologies related to their industrial and agricultural applications.

\section{Materials and methods}

\subsection{Extraction, oxidation and modification of humic acids}

South Moravian lignite mined in Mikulcice (mine Mir, near Hodonin, Czech Republic) was used as a source of humic acids. Humic acids were isolated by alkaline extraction. Air-dried lignite fraction was mixed with the aqueous solution of $0.5 \mathrm{~mol} \mathrm{~L}^{-1} \mathrm{NaOH}$ and $0.1 \mathrm{~mol} \mathrm{~L}^{-1} \mathrm{Na}_{4} \mathrm{P}_{2} \mathrm{O}_{7}$ and shaken for 3 hours. The suspension was centrifuged and the supernatant was treated with concentrated $\mathrm{HCl}$ to reach $\mathrm{pH} 1$ in order to precipitate the humic acid. HA were then treated overnight with a $0.5 \%(\mathrm{v} / \mathrm{v})$ $\mathrm{HCl}-\mathrm{HF}$ solution to remove residual ashes, dialyzed (Spectrapore dialysis tubes, $1000 \mathrm{M}_{\mathrm{w}}$ cut-off) against distilled water until chloride-free, and freeze-dried.

Oxidation of HA was performed as follows: $3 \mathrm{~g}$ of humic acids were mixed with $60 \mathrm{~mL}$ of different oxidizing agents $\left(\mathrm{H}_{2} \mathrm{O}_{2}\right.$ or $\left.\mathrm{HNO}_{3}\right)$ with corresponding concentrations ( 1 and $3 \%$ and 1 and $5 \%$ for hydrogen peroxide and nitric acids, respectively) and intensively stirred for $30 \mathrm{~min}$ at room temperature. Furthermore, the mixture was 3 times washed by $100 \mathrm{~mL}$ of distilled water in order to remove excess of oxidizing agent, filtered and freeze-dried.

Formaldehyde polycondensation was conducted under the conditions reported by (Ryabova and Mustafina, 2003). $0.3 \mathrm{~g}$ of humic acids were dispersed in $200 \mathrm{~mL}$ distilled water and the $\mathrm{pH}$ was adjusted to 7 by $0.1 \mathrm{~mol} \mathrm{~L}^{-1} \mathrm{NaOH}$. Further, the catalytic amount of $\mathrm{NaOH}(0.2 \mathrm{~mL}$, $1 \mathrm{~mol} \mathrm{~L}^{-1}$ ) was added followed by $1 \mathrm{~g}$ of a $35 \%$ aqueous solution of formaldehyde. The mixture was stirred for one hour at $60{ }^{\circ} \mathrm{C}$ under reflux. The product was treated with the concentrated $\mathrm{HCl}$ until $\mathrm{pH}$ about 1 in order to precipitate the humic acids. Those were then dialyzed (Spectra/Por ${ }^{\circledR}$ dialysis tubes, $1000 \mathrm{M}_{\mathrm{w}}$ cut-off) against distilled water until chloride-free and freeze-dried. The cartoon of the reaction for formaldehyde cross-linking inspired by the works of (Perminova and Hatfield, 2005; Ryabova and Mustafina, 2003) is reported in Fig. 1 and the obtained products are listed in Table 1.

The abbreviation of samples has been chosen in this way: original sample without any treatment is abbreviated "ORIG" and its formaldehyde cross-linked derivative is "ORIG_FM". The modified samples are marked as "OX", the suffix "P" stands for hydrogen peroxide and "N" for nitric acid. The number indicates the concentration of respective oxidizer and suffix “_FM" means that the modified HA sample was crosslinked as well.

For analyses carried out in liquid state, humic acids were converted into soluble sodium salts. $50 \mathrm{mg}$ of freeze-dried humic acids were suspended in $50 \mathrm{~mL}$ of distilled water. Automatic titrator Titroline alpha plus was employed to stepwise titrate the suspension until the humic acids were dissolved and $\mathrm{pH}$ reached 7.4. After that the system was let to equilibrate additional 60 minutes, then filtered and freezedried. In this way the sodium humates of original, oxidized and modified samples were obtained.

\subsection{Chemical and physical characterization of humic acids}

\subsubsection{Fourier transformed infrared spectrometry}

FTIR spectroscopy was used to assess the changes in chemical composition of both modified and cross-linked humic samples with respect to the composition of original sample. Conventional $\mathrm{KBr}$ pellet technique was employed. From 0.5 to $1 \mathrm{mg}$ of humic samples, previously dried at $105{ }^{\circ} \mathrm{C}$ for 4 hours in the oven, were mixed with $\operatorname{KBr}(1: 200$ $\mathrm{w} / \mathrm{w}$ ) in an agate mortar. Obtained mixture was squeezed to form a pellet and measured in the FTIR spectrometer Nicolet iS10. FTIR spectrometer was set to 128 scan and resolution was $4 \mathrm{~cm}^{-1}$ in air dry atmosphere. All obtained FTIR records were elaborated using Omnic 8.0.342 software. For the comparison of intensities of selected bands, the spectra were normalized to overlay the intensities (baselines) at 4000 and $500 \mathrm{~cm}^{-1}$, as indicated in (Ctvrtnickova et al., 2011).

\subsubsection{Elemental analysis}

Elemental analyses (carbon, hydrogen, nitrogen, and sulfur; the content of oxygen was taken as a difference from $100 \%$ ) were performed on a Perkin Elmer Series II CHNS/O Analyzer 2400 at Engineering Test Institute Brno. Table 1 shows the results of the organic elements on ash- and 

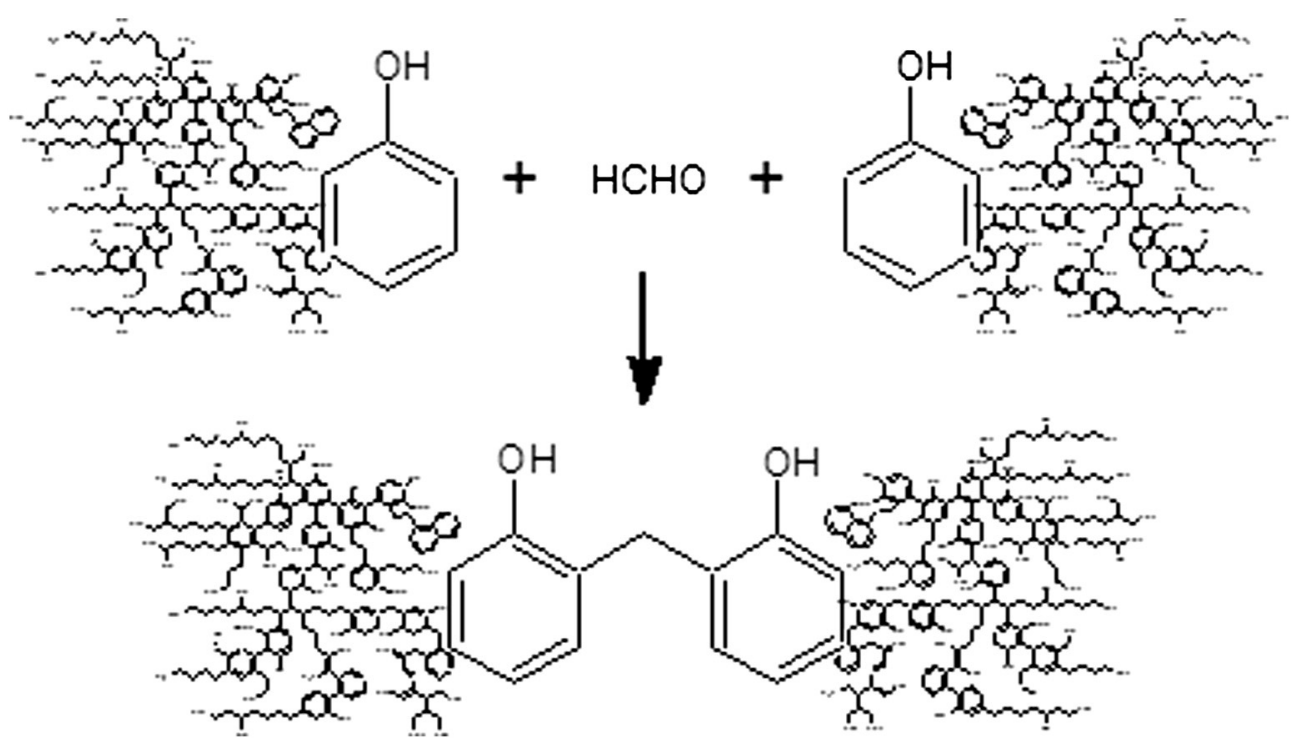

Fig. 1. Crosslinking of humic material using formaldehyde based on paper, repainted from (Perminova and Hatfield, 2005) with kind permission of the publisher.

moisture-free basis for the solid lignite humic acids samples. The deviation of measurement never exceeded $0.2 \%$.

\subsubsection{High performance size exclusion chromatography (HPSEC)}

Molecular size distributions of humic samples were assessed by an Agilent HPSEC system with a solvent pump, a Biosep S2000 column from Phenomenex (600 x $7.5 \mathrm{~mm}$ ), UV detector (UVD, $280 \mathrm{~nm}$ ) and a refractive index detector (RID). The column was preceded by a Biosep Guard column with a $0.2 \mu \mathrm{m}$ stainless-steel inlet filter. Flow rate was

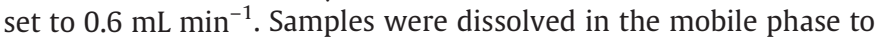
achieve the concentration of $0.6 \mathrm{mg} \mathrm{mL}^{-1}$, while the HPSEC eluent was a $50 \mathrm{mM} \mathrm{NaH}_{2} \mathrm{PO}_{4} \cdot \mathrm{H}_{2} \mathrm{O}$ solution adjusted to $\mathrm{pH} 7$ with $1 \mathrm{M} \mathrm{NaOH}$ in order to keep constant ionic strength and minimize potential ionic exclusion or hydrophobic interactions with the column stationary phase. All solutions were filtered through quartz filters (Glass Microfibre Filter Whatman International, Ltd.) before injection. Samples were loaded by the automatic injector with a $100 \mu \mathrm{L}$ sample loop. For the calculation of weight-average molecular weight $\left(\mathrm{M}_{\mathrm{w}}\right)$ Eq. (1) was applied:

$\overline{M_{w}}=\frac{\sum_{i} n_{i} M_{i}^{2}}{\sum_{i} n_{i} M_{i}}=\frac{\sum_{i} A_{i} M_{i}}{\sum_{i} A_{i}}$

In Eq. (1) $M_{i}$ are the molecular weights, $n_{i}$ are the number of molecules and $A_{i}$ are the heights of each i-th slice in the chromatogram, respectively. The HPSEC analyses were conducted in duplicate and the standard deviations of calculated $\mathrm{M}_{\mathrm{w}}$ never exceeded $4 \%$ for UVD and $5 \%$ for RID.

Standards of known $\mathrm{M}_{\mathrm{w}}$ were used for column calibration. Polysaccharides (186, 100, 23.7 and $12.2 \mathrm{~kg} \mathrm{~mol}^{-1}$ ) from Polymer Science Laboratories (UK) were chosen to calibrate the RI detector whereas sodium polystyrenesulphonates PSS $\left(169,123,30.9\right.$ and $\left.6.78 \mathrm{~kg} \mathrm{~mol}^{-1}\right)$ from Polymer Standards Service (Germany) were used to calibrate the UV detector. Calibration curves were semi-log linear over the range defined by standards and were used to obtain the molecular weights of humic samples. Each sample was measured twice and the standards were randomly distributed in the autosampler to check measurement reproducibility and state of the filter and the column. The deviation from repeated measurements never exceeded $5 \%$. Water was used to determine the total volume of the column $(22.8 \mathrm{~mL})$, whereas blue dextran (2000 Da) was used to measure the void volume (10.5 mL). The two detectors were employed were employed according to (Conte and Piccolo, 1999). First, the UVD, which determines the molecular absorptivity of chromophores at the wavelength of $280 \mathrm{~nm}$. Second, the refractivity index detector (RID). Although the RID is less sensitive than UVD, it is a nass-sensitive instrument independent of the chemical nature of the sample. In fact, whereas UVD can monitor only UV sensible molecular system (i.e. unsaturated molecules), RID provides information on the overall mass size distribution of humic samples (Conte and Piccolo, 1999). The RID responses equally to polymer concentration in all

Table 1

Elemental composition (atomic \%) of parental and pre-treated lignite HA samples and their respective ratios.

\begin{tabular}{|c|c|c|c|c|c|c|c|c|c|c|c|}
\hline \multirow[t]{2}{*}{ Sample } & \multirow[t]{2}{*}{ treatment } & \multicolumn{4}{|c|}{ [atomic. \%]* } & \multirow[b]{2}{*}{$\mathrm{C} / \mathrm{H}$} & \multirow[b]{2}{*}{$\mathrm{C} / \mathrm{O}$} & \multicolumn{2}{|c|}{ [wt. \%]* } & \multirow{2}{*}{$\frac{\mathrm{TGA}^{\mathrm{b}, \mathrm{c}}}{1 / 2}$} & \multirow{2}{*}{$\frac{\text { FTIR }}{1436 / 1508}$} \\
\hline & & $\mathrm{C}^{\mathrm{b}, \mathrm{c}}$ & $\mathrm{H}^{\mathrm{b}, \mathrm{c}}$ & $\mathrm{N}^{\mathrm{b}, \mathrm{c}}$ & $\mathrm{O}^{\mathrm{a}, \mathrm{b}, \mathrm{c}}$ & & & $w^{d}$ & $\mathrm{Ash}^{\mathrm{b}}$ & & \\
\hline ORIG & original & 39.9 & 43.9 & 0.67 & 15.5 & 0.91 & 2.57 & 6.9 & 0.9 & 0.52 & 1.15 \\
\hline ORIG_FM & formaldehyde & 43.2 & 40.8 & 0.76 & 15.3 & 1.06 & 2.83 & 5.8 & 1.1 & 0.56 & 1.24 \\
\hline OX_P_1 & $1 \% \mathrm{H}_{2} \mathrm{O}_{2}$ & 43.4 & 40.8 & 0.75 & 15.0 & 1.06 & 2.88 & 5.1 & 0.9 & 0.52 & 1.15 \\
\hline OX_P_1_FM & $1 \% \mathrm{H}_{2} \mathrm{O}_{2} ; \mathrm{FM}$ & 42.2 & 41.4 & 0.74 & 15.7 & 1.02 & 2.69 & 5.8 & 1.0 & 0.58 & 1.22 \\
\hline OX_P_3 & $3 \% \mathrm{H}_{2} \mathrm{O}_{2}$ & 42.5 & 41.9 & 0.76 & 14.9 & 1.01 & 2.85 & 4.5 & 0.9 & 0.51 & 1.16 \\
\hline OX_P_3_FM & $3 \% \mathrm{H}_{2} \mathrm{O}_{2} ; \mathrm{FM}$ & 41.7 & 42.2 & 0.81 & 15.3 & 0.99 & 2.73 & 5.4 & 0.6 & 0.70 & 1.19 \\
\hline OX_N_1 & $1 \% \mathrm{HNO}_{3}$ & 43.3 & 40.9 & 0.75 & 15.1 & 1.06 & 2.86 & 4.2 & 0.6 & 0.55 & 1.13 \\
\hline OX_N_1_FM & $1 \% \mathrm{HNO}_{3} ; \mathrm{FM}$ & 42.2 & 42.0 & 0.76 & 15.1 & 1.01 & 2.80 & 6.2 & 0.8 & 0.52 & 1.14 \\
\hline OX_N_5 & $5 \% \mathrm{HNO}_{3}$ & 43.0 & 41.9 & 0.74 & 14.4 & 1.03 & 2.98 & 4.2 & 0.6 & 0.55 & 1.14 \\
\hline OX_N_5_FM & $5 \% \mathrm{HNO}_{3} ; \mathrm{FM}$ & 42.0 & 42.0 & 0.73 & 15.3 & 1.00 & 2.75 & 6.5 & 0.6 & 0.67 & 1.24 \\
\hline
\end{tabular}

${ }^{\mathrm{a}}$ calculated by difference, ${ }^{\mathrm{b}} \mathrm{dry}$ sample, ${ }^{\mathrm{c}}$ ash free, ${ }^{\mathrm{d}}$ moisture content. 
molecular weight regimes with the exception of low molecular weights, where the polymer end-groups represent a non-negligible portion of the molecules' mass and do change the refractive index (Wu, 2004).

\subsection{4. ${ }^{1} \mathrm{H}$ NMR relaxometry experiments}

The HA samples were analyzed in a wet state. The hydration procedure consisted in the addition of $0.5 \mathrm{~mL}$ of water to $1 \mathrm{~g}$ of each HA sample. Then, the samples were left 24 hours to equilibrate. Finally, the excess of water was allowed to slowly evaporate in standard desiccators for several days. Afterwards samples were stored in a desiccator with a vessel filled by water at $25 \pm 2{ }^{\circ} \mathrm{C}$ for 21 days, to prevent the water desiccation and achieve equilibration. According to the literature (Hurraß and Schaumann, 2007), after 21 days the equilibrium between HS and water atmosphere can be considered achieved.

Proton longitudinal $\left(\mathrm{T}_{1}\right)$ relaxation times were acquired on a Stelar Spinmaster-FFC-2000 Fast-Field-Cycling Relaxometer (Stelar s.r.l., Mede, PV-Italy) at a constant temperature of $20^{\circ} \mathrm{C}$.

The fundamentals of FFC-NMR relaxometry are reported elsewhere (Conte and Alonzo, 2013; Ferrante and Sykora, 2005; Kimmich and Anoardo, 2004). Briefly, the technique is based on the cycling of the Zeeman magnetic field $\left(B_{0}\right)$ through three different values usually indicated as $B_{\text {pol }}$ (polarization field), $B_{\text {relax }}$ (relaxation field), and $B_{\text {acq }}$ (acquisition field). $B_{p o l}$ is applied for a period of time during which magnetization saturation and sensitivity enhancement are achieved. Then, the magnetic field is switched to a new one, $B_{\text {relax }}$, applied for a period $(\tau)$ during which the intensity of the magnetization relaxes towards a new equilibrium condition. Finally, the application of a magnetic field $B_{\text {acq }}$ together with a ${ }^{1} \mathrm{H} 90^{\circ}$ pulse makes the magnetization observable. $\mathrm{B}_{\text {pol }}$ was not applied for the present study.

The experimental relaxometric setting consisted of: 1 . acquisition of the longitudinal magnetization evolution at value of a relaxation magnetic field of $464 \mathrm{mT}$ (i.e. proton Larmor frequency of $20 \mathrm{MHz}$ ) applied for a period of time $(\tau)$ arrayed with 64 values varying from 1 to $800 \mathrm{~ms} . \tau$ array was chosen in a geometrical progression in order to cover the entire relaxation curve of interest; 2 . a recycle delay of $4 \mathrm{~s}$; 3. a $380 \mathrm{mT}\left(\omega_{\mathrm{L}}=16.3 \mathrm{MHz}\right)$ acquisition field with a ${ }^{1} \mathrm{H} 90^{\circ}$ pulse of $9 \mu$ in order to obtain observable magnetization and reveal free induction decay (FID) with a time domain of $100 \mu$ s sampled with 512 points. 2 scans were accumulated. All the experimental data were acquired with the AcquNMR V95® software provided by Stelar.

The recovery curves retrieved by applying the sequence outlined above were elaborated by the UPEN algorithm (Alma Mater Studiorum, Università di Bologna, Italy) (Borgia et al., 1998; Borgia et al., 2000) with the aim to obtain the $\mathrm{T}_{1}$ distributions and, therefore, information on pore distributions and water interactions (Bayer et al., 2010; Conte and Alonzo, 2013).

\subsection{Thermal analysis and sample preparations}

\subsubsection{Differential scanning calorimetry (DSC) measurement}

TA Instruments Differential Scanning Calorimetry (DSC) Q200 equipped with a cooling accessory RCS 90 was employed in order to determine the melting enthalpy of freezable water into HA structure (Kucerik et al., 2012). The temperature and heat scale were calibrated using distilled water and In standards. An empty pan was used as a reference during the experiments. Thermal (freezing/thawing) experiment started at $40{ }^{\circ} \mathrm{C}$, then the sample was cooled down to $-70{ }^{\circ} \mathrm{C}$ at $3{ }^{\circ} \mathrm{C} \mathrm{min}{ }^{-1}$, isothermally kept at $-70{ }^{\circ} \mathrm{C}$ for $2 \mathrm{~min}$. Then the heating run from $-70{ }^{\circ} \mathrm{C}$ to $40{ }^{\circ} \mathrm{C}$ at $10{ }^{\circ} \mathrm{C} \mathrm{min}-1$ was conducted. Experiments were carried out under dynamic atmosphere of nitrogen, flow rate

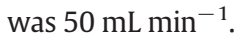

Sample of approximately 1-4 mg was placed in aluminum sample pan (TA Instruments, Tzero ${ }^{\circledR}$ technology) and the excess of water (milli-Q) was added to HA sample. Surplus water was allowed to evaporate at room temperature until the desired water content was obtained ( $1 \mathrm{~g}$ water/1 $\mathrm{g} \mathrm{HA}$ ). Then the pan was hermetically sealed and left to additional equilibration at room temperature for 1 day. Prepared samples were then measured repeatedly after $1,5,8,14$ and 21 days of their preparation. Each sample was measured 2-3 times, standard deviations never exceeded $4 \%$ of average volume.

\subsubsection{Thermogravimetrical analysis (TGA)}

TA Instruments thermogravimetric analyzer Q5000IR with the dynamic nitrogen atmosphere $5 \mathrm{~mL} \mathrm{~min}{ }^{-1}$ was used in order to monitor the mass losses at $40,50,70$ and $90{ }^{\circ} \mathrm{C}$. In this way the quantitative information on the water fractions adsorbed by different binding energies were obtained. In addition thermogravimetry was also used to get total water content in humic acids represented by a mass loss in the temperature interval $25-150{ }^{\circ} \mathrm{C}$ determined under dynamic atmosphere of nitrogen $25 \mathrm{~mL} \mathrm{~min}^{-1}$ (Table 1 ). The heating rate was $10{ }^{\circ} \mathrm{C} \mathrm{min}-1$ from the room temperature to $250{ }^{\circ} \mathrm{C}$. This information was further used also for the precise determination of water content during HA/water sample preparation.

In order to determine the thermo-oxidative stability and degradability of studied samples the TGA was used under the dynamic atmosphere of air with the flow rate of $25 \mathrm{~mL} \mathrm{~min}^{-1}$ with the heating rate $10{ }^{\circ} \mathrm{C}$ per minute from the room temperature to $650{ }^{\circ} \mathrm{C}$. The samples were measured in triplicates, the standard deviation of mass losses never exceeded $2 \%$.

In all TGA analyses the open platinum pan was used as a sample holder. Typically, mass of samples was always around $5 \mathrm{mg}$. Prior to the analysis the device was calibrated on temperature and mass change using procedures recommended by provider. All of the experimental dates were processed by means of TA Universal Analysis 2000 software.

Prior to the moisture content analysis, humic acids were stored in moisturizing containers, under controlled different relative humidity conditions at $25 \pm 2{ }^{\circ} \mathrm{C}$ for 21 days. The atmospheres were kept by appropriate supersaturated water/ salts systems. For this purpose, $\mathrm{Na}_{2} \mathrm{Cr}_{2} \mathrm{O}_{7},\left(\mathrm{CH}_{3} \mathrm{COO}\right)_{2} \mathrm{Mg}$ and $\left(\mathrm{NH}_{4}\right)_{2} \mathrm{SO}_{4}$ were used and 55, 61 and $79 \%$ relative humidity $(\mathrm{RH})$ atmosphere were obtained, respectively.

\section{Results and discussion}

\subsection{Chemical and physicochemical properties of humic samples}

\subsubsection{Elemental analysis}

Table 1 shows the list of samples, the type of oxidation, the chemical modification, the elemental composition of each sample and the results extracted from thermogravimetry and FTIR spectra. Carbon content was moderately increased after all pre-treatments. The lowest content of carbon was measured in sample ORIG, while the largest $C$ content was determined in samples OX_P_1. Higher carbon content in modified samples can be explained by the incorporation of methylene groups $\left(-\mathrm{CH}_{2}-\right)$ into humic acids structure as follows from the scheme reported in Fig. 1. Nitrogen content slightly increased in all samples with respect to the ORIG sample. This is caused by nitrification of the structure in case of nitric acid treatment (Kucerik et al., 2003). The increase in relative nitrogen content after crosslinking is quite peculiar since no $\mathrm{N}$ atoms are supposed to be introduced into the structure during cross-linking reactions. In line with the literature data about the influence of small molecules on physical structure of humic acids (Conte et al., 2007; Kucerik et al., 2007; Simpson, 2002), it can be assumed that presence of formaldehyde influences the physical structure of humic acids, causing possible leakage of some fractions during purification after synthesis. The loss of some fractions can artificially increase the content of $\mathrm{N}$ in cross linked humic acids. The oxygen content was almost the same for all samples, while samples OX_P_3 and OX_N_5 represented samples with the lowest oxygen content. Those samples were oxidized by stronger oxidizing agents than the OX_P_1 and OX_N_1, which probably caused either the decomposition of humic parts and/or an increase in number of highly soluble molecules during sample manipulation. The air oxidation of lignite reported recently (Kučerík et al., 2008) brought 
similar results and revealed that oxidation of lignite consists of several phases, in which the yield of regenerated humic acids can even decrease, when weaker oxidative conditions are used due to the preferential oxidation of less stable moieties (typically aliphatic molecules) and oxygen-containing functionalities in parental lignite. This is reflected also in the $\mathrm{C} / \mathrm{O}$ ratio, which indicates the hydrophilicity degree of a humic matter. Lower value of this ratio is associated with higher content of oxygen functional groups and consequently also higher hydrophilicity. The $\mathrm{C} / \mathrm{O}$ ratio indicated that a significant difference caused the nitric acid treatment, the highest value was observed for sample OX_N_5, which indicates an intensive decomposition of oxygen containing groups during the oxidation. The crosslinking reactions caused scattered changes in this value, which is caused probably by interaction of formaldehyde with the structure causing above-mentioned leakage during purification.

\subsubsection{FTIR spectroscopy}

FTIR spectroscopy of humic acids showed the typical spectra of lignite humic acids already present in literature e.g. (Tatzber et al., 2007). In this study, as an example reported in Fig. 2, only the FTIR spectra of ORIG_FM, OX_N_5 and OX_N_5_FM are reported (Fig. 2). To improve their readability, the spectra in Fig. 2 are intentionally shifted.

Fig. 2 shows two intensive peaks around 2926 and $2848 \mathrm{~cm}^{-1}$, which are attributed to $-\mathrm{CH}_{2}$ - and $-\mathrm{CH}_{3}$ vibrations; strong sharp peaks at $1715 \mathrm{~cm}^{-1}(\mathrm{C}=\mathrm{O}$ of $\mathrm{COOH})$ and $1605 \mathrm{~cm}^{-1}$ ( $\mathrm{C}=\mathrm{C}$ stretching, $\mathrm{C}=\mathrm{O}$ stretching of $\mathrm{COO}^{-}$, ketonic $\mathrm{C}=\mathrm{O}$ and aromatic $\mathrm{C}=\mathrm{C}$ conjugated with $\mathrm{COO}^{-}$); a peak around $1508 \mathrm{~cm}^{-1}$ ( $\mathrm{N}-\mathrm{H}$ deformation, $\mathrm{C}-\mathrm{N}$ stretching vibration, $\mathrm{C}=\mathrm{C}$ aromatic bounds); a weak peak at $1436 \mathrm{~cm}^{-1}$ (aliphatic $\mathrm{C}-\mathrm{H}$ bending, and $\mathrm{COO}-$ asymmetric stretching, and possibly $\mathrm{C}=\mathrm{C}$ and $\mathrm{C}=\mathrm{N}$ plane vibrations of heterocycles); an intensive peak around $1215 \mathrm{~cm}^{-1}$ (aromatic C, C-O stretch); and a weak peak around $1050 \mathrm{~cm}^{-1}$ (C-O of polysaccharides and/or Si-O).

The spectra of the remaining samples had similar patterns with small quantitative differences. Table 1 shows the comparison of the intensities corresponding to the aliphatic $\mathrm{C}-\mathrm{C}\left(1436 \mathrm{~cm}^{-1}\right)$ and aromatic $\mathrm{C}=\mathrm{C}\left(1508 \mathrm{~cm}^{-1}\right)$ moieties. The increasing ratio between these two bands indicates the introduction of new aliphatic bonds, thereby confirming the chemical change of the humic structure after crosslinking. The comparison of other peak intensities was not possible due to the high heterogeneity of humic acids, which causes overlapping of the bands super-positions.

\subsubsection{Thermogravimetry}

The influence of the modification on the thermo-oxidative stability was tested using thermogravimetry. Fig. 3 shows a typical

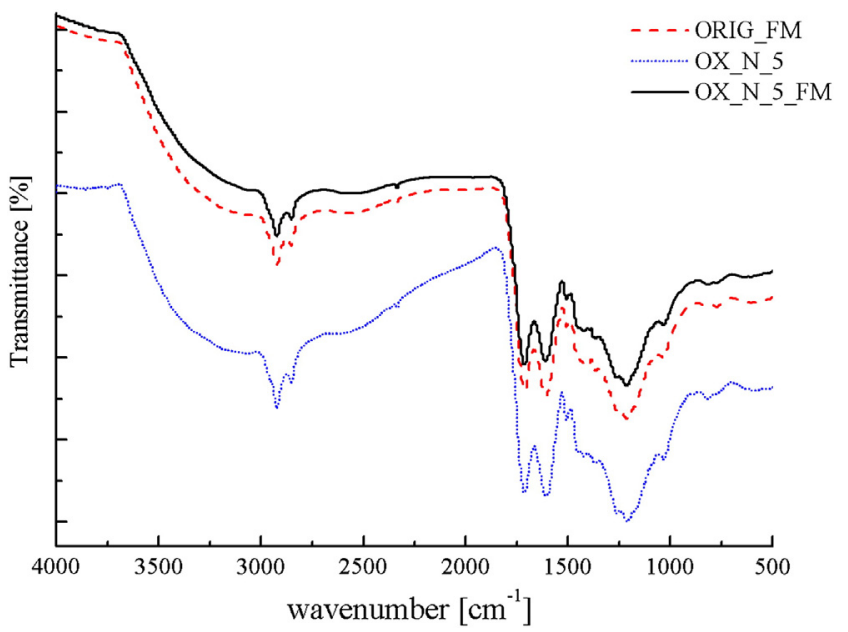

Fig. 2. Comparison of transmittance FTIR spectra for selected samples of HA samples. Yaxes is artificially shifted to increase the readability of the records.

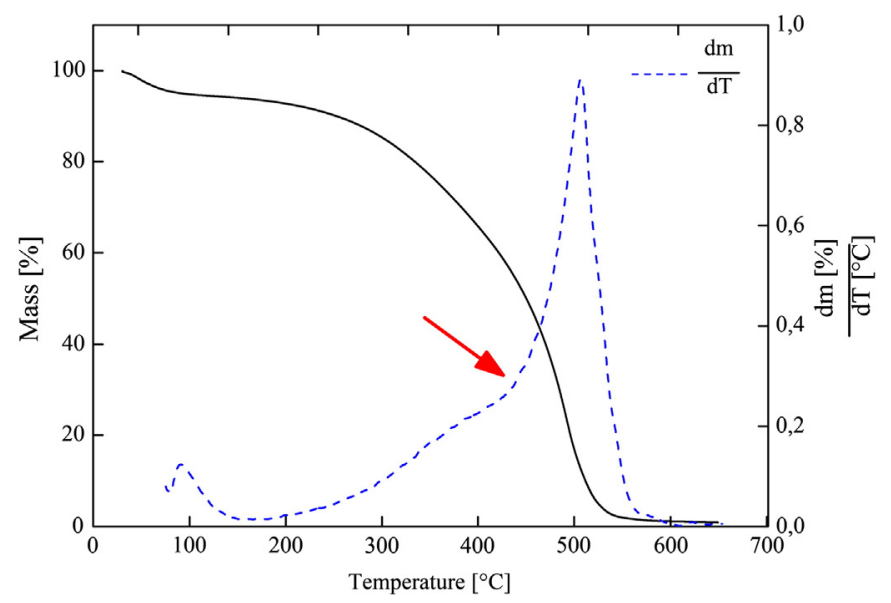

Fig. 3. TGA and DTG record of the sample ORIG_FM, the arrow indicates the change in mechanisms, i.e. the onset of the second degradation step.

thermogravimetry record including its negative first derivative (DTG). The incombustible rest of the mass after the experiment, i.e. the ash content, was approximately $1 \%$ (Table 1 ). In all samples, the progressive mass loss, which occurred up to $160{ }^{\circ} \mathrm{C}$, was caused mainly due to the loss of adsorbed moisture. For all samples, the total equilibrium moisture content was determined in the interval from 4.2 to $6.9 \%$. The first derivative of thermogravimetric curves of humic samples showed two peaks in the temperature interval between $180-600{ }^{\circ} \mathrm{C}$, which confirmed a two-step-degradation of lignite humic acids also observed elsewhere (Kucerik et al., 2004). As shown in Fig. 3, first step occurred between $180-450{ }^{\circ} \mathrm{C}$. It is associated with larger mass loss connected with decomposition of labile humic components, typically aliphatic moieties and functional polar groups (Kucerik et al., 2004). The second step can be seen in temperature interval between $450-600{ }^{\circ} \mathrm{C}$. The determined mass losses and their ratio are reported in Table 1. All samples showed either the same or higher ratio between mass losses than ORIG sample. Similarly the crosslinking reactions caused mostly increase in the mass loss ratio with the exception of OX_N_1_FM sample, which showed a slight decrease. Thus both types of modification, i.e. oxidation and crosslinking brought an increase in the labile pool with respect to original samples. This confirms the increase in content of aliphatic structures in cross-linked materials.

The thermogravimetry analyses indicate that both oxidation treatment and crosslinking caused structural destabilization of humic samples. The decrease upon oxidation is in line with literature data, it was explained as the consequence of oxidative disruption of the chemical structure (Kucerik et al., 2005). In case of crosslinking, the decreased stability can be related to the changes in physical structure caused by the aliphatic bridges cross-linking. The increased system porosity supports diffusion of air and enhances the segments mobility due to lower structural compactness. Both cases, i.e. the increase in the reactive surfaces and the decrease of structural compactness, would decrease the temperature of thermo-oxidative degradation onset. This explanation is supported by hydration studies reported in following paragraphs.

\subsubsection{High performance size exclusion chromatography}

The influence of the pre-oxidation and cross-linking of humic acids was studied by using HPSEC. Fig. 4 reports the results obtained from both UVD and RID, in both cases a bimodal distribution was detected.

The intense peak at the retention time of 23 min was due to the largest components of the humic sample. Conversely, smaller HA components were detected at the largest retention times. It has been already shown that the largest molecular size fractions are made mainly by aromatic, alkyl and potentially carbohydrate-like systems. The length of the carbohydrate-like and the alkyl chains decrease as molecular size decreases. Progressive reduction of aromatic carbon atoms was also 


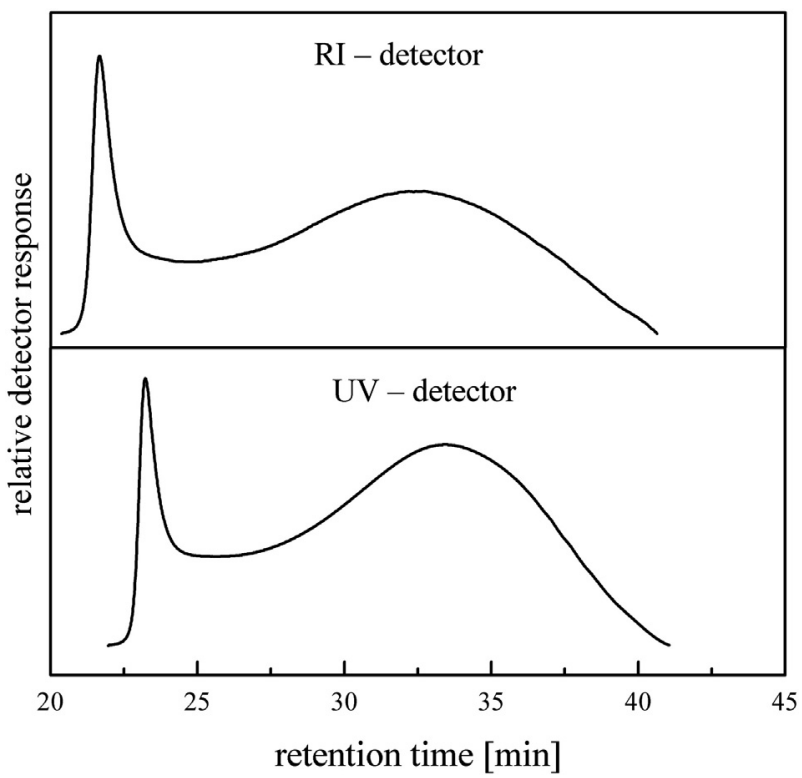

Fig. 4. Exemplary HPSEC chromatograms of the $1 \%$ HNO3 pre-treated sample (OX_N_1) detected by UV detection (UVD) at $280 \mathrm{~nm}$ and refractive index (RID).

observed with decreasing molecular size of the separated fractions. Finally, the largest amount of hydrophilic molecules has been reported in the low molecular fractions (Conte et al., 2006).

Weight-average molecular weights $\left(M_{w}\right)$ determined from both detectors are reported in Table 2. The comparison between original and modified humic acids shows that both oxidation and formaldehyde modification induced an increase in the molecular size of humic acids. From this point of view, the cross-linking of humic molecules resulted in formation of higher molecular weight polymer-like structures, which verifies the introduction of new covalent bonds or indicates a leakage during the procedure. The comparison of the parental sample ORIG with humic acids oxidized using nitric acid and hydrogen peroxide showed an increase in $M_{w}$ as well. This is in line with previous discussion about several stages of oxidation favoring oxidation of specific parts of humic acids (Kučerík et al., 2008). The change in molecular weight indicates that those parts were mostly aliphatic moieties containing functional groups, which have lower tendency to form aggregates and thus, their degradation during oxidation caused an increase in $M_{w}$. The exception from this explanation seems to be the $5 \%$ nitric acid, which is strong enough to degrade also other parts than only aliphatic moieties, because the increase in $M_{w}$ is insignificant in comparison with weaker hydrogen peroxide or lower concentrated $1 \%$ nitric acid.

Table 2

Weight-average (Mw) of parental and pre-treated lignite HA samples. UVD stands for data obtained from UV detector at $280 \mathrm{~nm}$ and RID means refractivity index.

\begin{tabular}{lll}
\hline Sample & $\begin{array}{l}M_{\mathrm{w}}(\mathrm{UVD}) \\
{\left[\mathrm{kg} \cdot \mathrm{mol}^{-1}\right]}\end{array}$ & $\begin{array}{l}M_{\mathrm{w}}(\mathrm{RID}) \\
{\left[\mathrm{kg} \cdot \mathrm{mol}^{-1}\right]}\end{array}$ \\
\hline ORIG & 19.6 & 54.1 \\
ORIG_FM & 26.0 & 73.4 \\
OX_P_1 & 22.0 & 60.8 \\
OX_P_1_FM & 30.0 & 85.2 \\
OX_P_3 & 23.3 & 63.3 \\
OX_P_3_FM & 25.7 & 71.0 \\
OX_N_1 & 24.9 & 64.6 \\
OX_N_1_FM & 23.0 & 65.9 \\
OX_N_5 & 20.5 & 57.8 \\
OX_N_5_FM & 23.3 & 64.6 \\
\hline
\end{tabular}

\subsection{Water uptake and water holding capacity of cross-linked materials}

\subsubsection{Moisture adsorption}

The water uptake and water holding capacity belong to the most important properties of humic substances. In natural systems, there are several ways how humic substances can come to the contact with water. To mimic those processes, the samples were first exposed to the controlled atmosphere in a moisturizing container.

Fig. 5a shows an example of the TGA curves measured at four different temperatures obtained for sample OX_N_5_FM, placed into the moisturizing chamber with $55 \%$ relative humidity ( $\mathrm{RH}$ ) for 21 days. Mass losses correspond to the moisture evaporation. Slopes of the curves show that the rate of evaporation of water is the largest at the beginning of the process. Approximately after ten minutes the evaporation is almost finished, i.e. the mass loss is close to zero. The determined decrease in mass corresponds to the amount of water adsorbed on specific sites in HA bond by weaker or stronger forces, depending on the temperature used in the experiment. Fig. $5 \mathrm{~b}$ shows the quantitative differences of adsorbed water under three different RH conditions. Amount of evaporated moisture was determined in the range from 5 to $10 \%$ for all samples.

The changes in the moisture contents, i.e. difference between water contents on parental and cross-linked samples, are reported in Fig. 6. Here, the y axis shows the change in percentage related to the total sample mass including the dry part. Conversely, the small numbers show this change as a percentage related solely to the water content. Therefore, the positive values of the numbers given in Fig. 6 indicate higher moisture adsorption of samples without cross-linking, and conversely, negative values indicate higher moisture adsorption on cross-linked samples. We do not report the results obtained for $61 \% \mathrm{RH}$, because their values were always between results obtained for RHs $55 \%$ and $79 \%$. Results for 55 \% RH in Fig. 6a shows that the cross-linking induced mostly the decrease in moisture adsorbed by humic samples. The exception is sample OX_N_5, which showed an increase for all adsorbed fractions. The highest difference between cross-linked and its parental substrate $27.4 \%$ at $90{ }^{\circ} \mathrm{C}$ for OX_P_3.

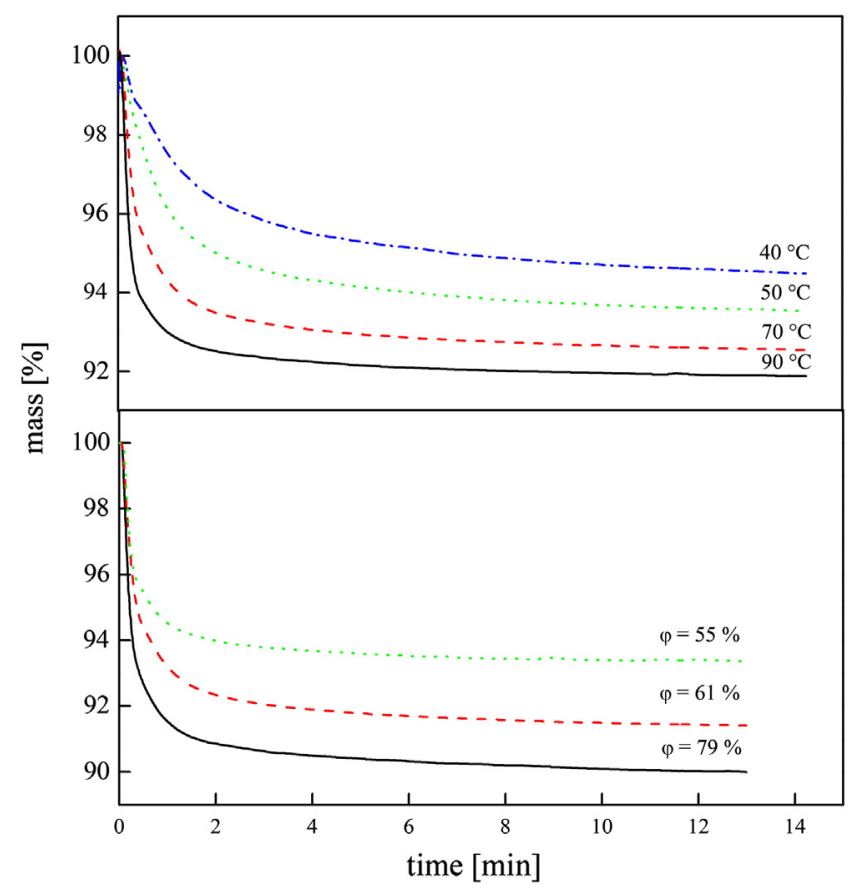

Fig. 5. Exemplary TGA record of pre-treated sample (OX_N_5_FM): Above, moisture evaporation from sample placed for 21 days in $55 \%$ relative humidity chamber and detected under indicated isothermal conditions; Below, moisture evaporation at $70{ }^{\circ} \mathrm{C}$ for sample previously stored in chamber with 55,61 and $79 \%$ relative humidity. 


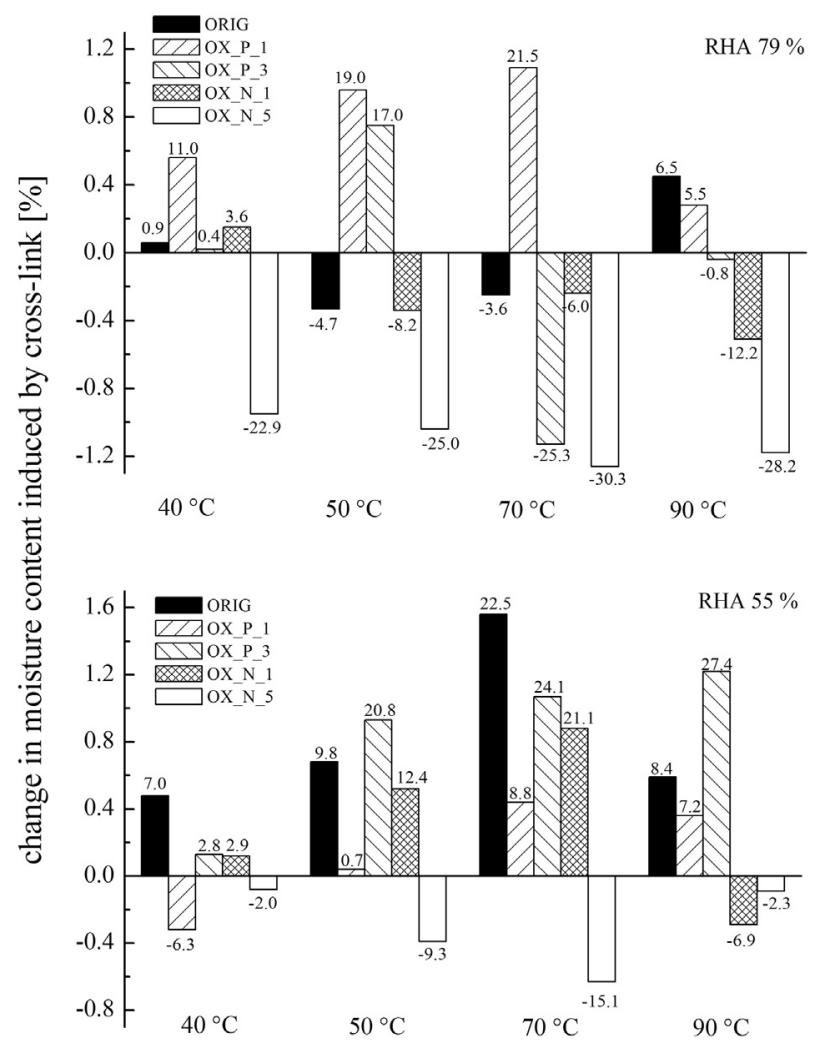

Fig. 6. Moisture content determined by TGA for HA samples stored under specific atmosphere with relevant relative humidity (RH $55 \%$ and $79 \%$, respectively).

The situation has significantly changed, when the samples were exposed to $79 \%$ RH. In this case, also the sample OX_N_5 adsorbed larger portion of moisture after crosslinking, while the other samples gave mixed results. The increase in this case was around $30 \%$ of total moisture content.

This shows that the surface of cross-linked materials is generally more susceptible for wetting at higher $\mathrm{RH}$. Because the number of polar groups did not change significantly (see results of elemental analysis and FTIR spectra), it can be concluded that cross-linking caused a change in the physical structure of humic acids, thereby supporting the water condensation at higher partial water pressure. In carbonaceous materials, water molecules adsorb onto oxygenated surface sites and act there as nuclei for the formation of larger three-dimensional water clusters or water molecule bridges (WaMB). Under appropriate conditions (e.g. high total pressure or partial water pressure), these clusters connect, either along the surface of across the pore, and pore filling can occur (Brennan et al., 2002; Liu and Monson, 2005; McCallum et al., 1999). Therefore, the determining factor for water condensation is the polar groups density (Brennan et al., 2002). In other words, the distance of the functional groups is a decisive factor in water condensation at different RHs.

It is known that water in soil organic matter can form under appropriate conditions nanodroplets that bridge and stabilize soil organic matter segments (Aquino et al., 2011). Our results indicate that in parental humic acids, the polar groups are close to each other, whereas in the cross-linked humic acids the structural rigidity prevents this kind of aggregation. For this reason, groups are more separated in the latter system Distance between functional groups explnais the difference in structural compactness retrieved by thermogravimetry. At low $\mathrm{RH}$, the condensation in parental humic acid occurs as a bridging of multiple functional groups, already forming the nanodroplets. Conversely, in cross-linked material water condenses at separated functional groups, which are in a large distance to be bridged by the formation of nano-droplets. At higher RH, the water condensation continues and supports the conditions for the formation of nanodroplets also in cross-linked material. Due to the separation of functional groups, the nanodroplets are larger in cross-linked humic acids. The formation of nanodroplets between separated functional groups and their dependency on the distance have been reported recently, based on the experimental and modelling approach dealing with cation-water-molecule bridges in sapric histosol (Kunhi Mouvenchery et al., 2013).

\subsubsection{Distribution of water in swollen samples}

The other possibility to mimic the natural hydration processes is the direct addition of water excess to humic acids. It is recognized that after wetting stage, which can take from minutes to months in some organic substrates (Jaeger et al., 2010), water molecules penetrate and distribute into the structure causing its swelling (Schaumann et al., 2005). This is accompanied with the interruption of weak interactions stabilizing the supramolecular HS structure (Diehl, 2013; Jaeger et al., 2010; Kucerik et al., 2012).

Fig. 7 reports distribution of longitudinal relaxation times obtained by applying the UPEN algorithm (see Materials and Methods). It must be stated that the weaker the interaction between water and the porous material, the higher is the water molecular mobility, thereby leading to longer $\mathrm{T}_{1}$ values. Conversely, as the interactions are stronger, water mobility is more restricted, and longitudinal relaxation time is shorter (Bayer et al., 2010; De Pasquale et al., 2012; Jaeger et al., 2010). Water mobility restriction is affected by the dimension of pores in a solid system. In fact, water confined in small sized pores is more constrained than that moving in large sized porous (De Pasquale et al., 2012). On the other hand, chemical bonds also affect molecular mobility and, hence, $\mathrm{T}_{1}$ values. As an example, water in contact either with carbonaceous materials (Conte et al., 2013b), or inorganic solids (Conte et al., 2013a), may form unconventional hydrogen bonds, which reduces water mobility, thereby producing shorter longitudinal relaxation times.

All samples, except for ORIG_FM, showed only one $T_{1}$ component (Fig. 7). It is important to note that the oxidized samples showed broader $\mathrm{T}_{1}$ distributions as compared to the modified samples. This suggests that cross-linking caused structural changes leading to the unification of pores in humic acids. In fact, the hydration of humic acids is connected with progressive disruption of weak interactions stabilizing their physical structure during which the processes such as dissolution, swollen cavity disruption followed by water redistribution, take place (Kucerik et al., 2012). In some humic acids this redistribution might be non-uniform (Kucerik et al., 2012). Introduction of covalent bonds stabilizes the structure in terms of formation of permanent pores and cavities, which cannot be easily disrupted upon swelling. This observation, as well as the increase in pores size, indicates that water can easily penetrate into the cross-linked structure, because it has to overcome less restrictions connected with wetting and swelling of cavities of small dimensions. This should be reflected in larger water holding capacity and faster hydration kinetics.

\subsubsection{Water holding capacity and kinetics of water uptake}

In order to quantify the water holding capacity and rate of water penetration, the amount of hydration water was successively determined. In principle, water molecules located in the intimate contact with humic acid do not freeze due to their lower mobility, which prevents their participation in ice formation (Kucerik et al., 2012). Fig. 8 reports the DSC thermograms explaining this experiment. In principle, humic acid with certain water content was cooled and heated and the formation of ice was monitored as the enthalpy of ice melting. Ice is formed from freezable water, its content can be expressed as $\mathrm{W}_{\text {freezable }}=$ $\mathrm{W}_{\text {total }}-\mathrm{W}_{\text {non-freezing. }}$. Total water content $\mathrm{W}_{\text {total }}$ is constant in the course of the experiment while the non-freezing water content $\mathrm{W}_{\text {non-freezing }}$ is progressively increased. This causes a decrease in content of freezable water $\mathrm{W}_{\text {freezable, }}$ which is proportional to its melting peak area. Therefore, as a 

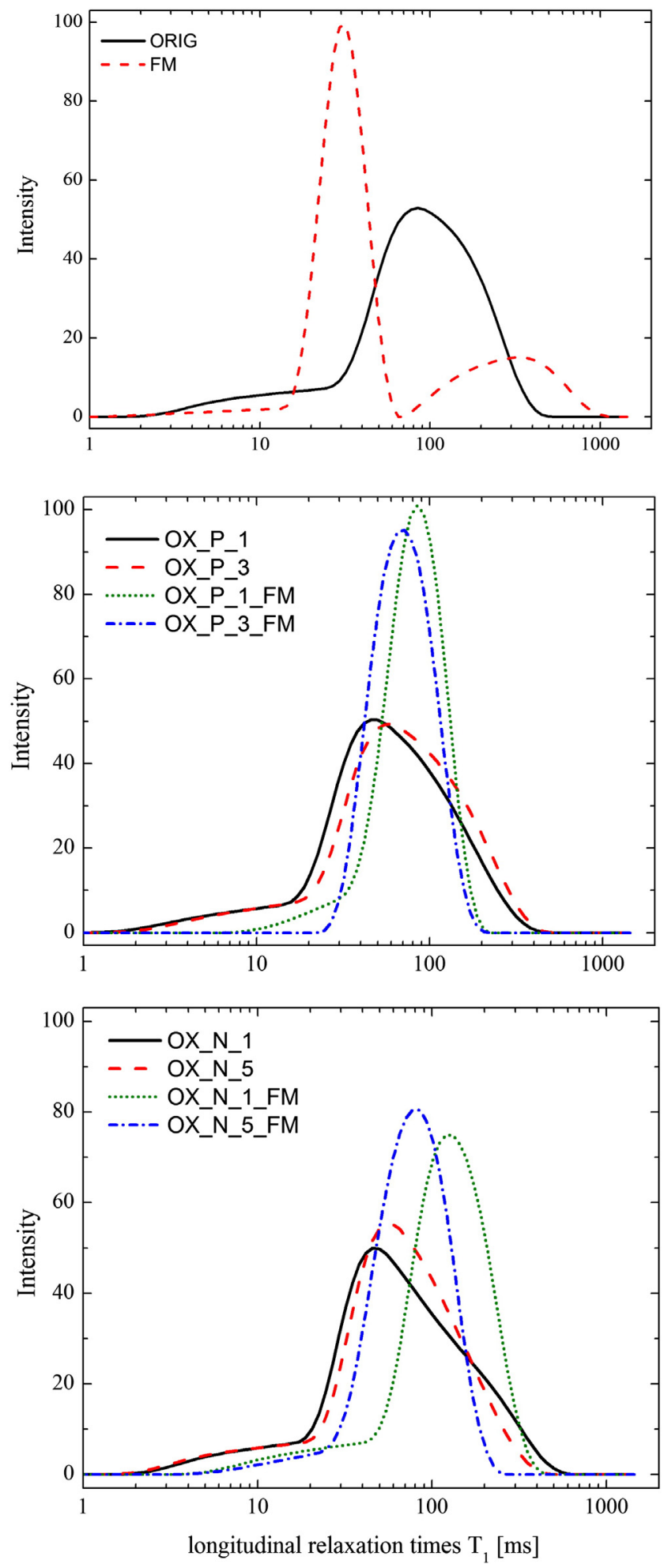

Fig. 7. Representative distributions of $T_{1}$ relaxation times curves of water in wetted HA.

measure of the progressive hydration, the decreasing peak area corresponding to the melting of ice formed by freezable water fraction was used. As it can be seen in Fig. 8 the peak area is reduced after 21 days of hydration.

Table 3 summarizes the comparison of enthalpies of ice melting in all samples $(\sim 1 \mathrm{~g}$ water $/ 1 \mathrm{~g} \mathrm{HA})$ over the period of 21 days. Column 0 day represents theoretical values of melting enthalpy for water added to humic acids and assuming no interaction between water and structure of HA, i.e. situation before swelling of the humic structure takes part. It

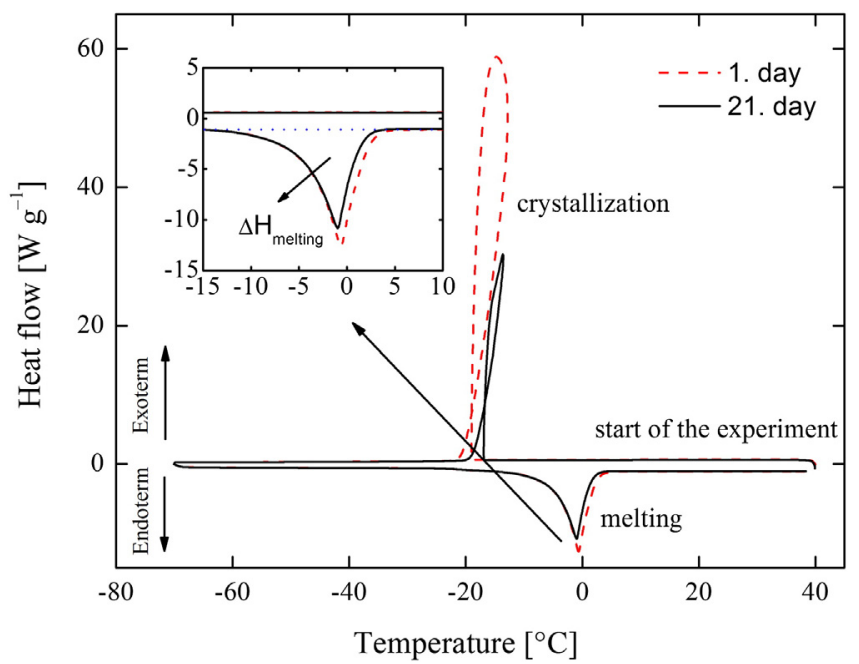

Fig. 8. Comparison of peaks corresponding to melting of ice formed by freezable water in OX_N_5_FM, measured by DSC 1st and 21st day after preparation.

can be seen the initial steep decrease after 1 st day followed by a moderate decrease in the melting enthalpy. This moderate trend decelerated around 8th day of hydration experiment. After this time, only a small difference in melting enthalpy can be observed. The values of enthalpy were almost constant after 21 days and only small changes occurred afterwards. The results reveal different kinetic process related to the uptake of water molecules onto and into humic structure.

The last column in Table 3 reports the relative affectivity of crosslinking with respect to the water holding capacity determined after 21 days of hydration. It can be seen that both oxidation of parental humic acids as well as cross-linking increases the ability of humic structure to accommodate water. The term "Hydration" value has the meaning of the non-freezing water, i.e. water, which does not freeze when cooled down, distributed either in small pores or as the fraction located in the intimate contact with surface of humic acids. In all cases, the crosslinking caused the increase in water holding capacity. The highest water holding capacity showed sample OX_N_5_FM, which gave value $92 \%$. In other words, the hydration of this sample was $0.92 \mathrm{~g}_{\mathrm{H} 2 \mathrm{O}} / \mathrm{g}_{\mathrm{HA}}$. Comparison of original humic acids "ORIG" with humic and fulvic acids collected from different localities shows that lignite humic acids investigated in this work have naturally lower abilities to hold water (Kucerik et al., 2012). Modification caused the three fold increase in water holding capacity, which is value comparable with hydrophilic polysaccharides, e.g. (Mlcoch and Kucerik, 2013; Prusova et al., 2010, 2013). We hypothesize that this is partially caused by the separation of functional groups in cross-linked humic acids, which supports wetting of inner pores.

The anticipated increase in hydration kinetics can be observed in the column 0-1. day. Results in Table 3 show that the modified samples had significantly faster water uptake in comparison with their parental samples. This confirms the previous conclusions about increase in pore size after modification and easier penetration of water into the structure.

\section{Conclusions}

South Moravian lignite humic acids were oxidized using nitric acid and hydrogen peroxide and then cross-linked using formaldehyde. The chemical and physical structures of products were analyzed using analytical and physical-chemical methods. The elemental composition of humic acids was not dramatically changed after modification and the process of cross-linking caused the slight increase in aliphatic content and apparent molecular weight size. Thermo-oxidative tests revealed that cross-linking decreased the thermo-oxidative stability of cross-linked products, which was ascribed to the increase in porosity 
Table 3

The summary of the results obtained from DSC experiments.

\begin{tabular}{|c|c|c|c|c|c|c|c|c|c|c|c|}
\hline \multirow[t]{2}{*}{ Sample } & \multicolumn{6}{|c|}{ Melting enthalpy $\left[\mathrm{J} \mathrm{g}^{-1}\right]$} & \multirow[b]{2}{*}{$\mathrm{H}_{2} \mathrm{O}$ [wt. \%] } & \multicolumn{4}{|c|}{ Change of melting enthalpy $\left[\mathrm{J} \mathrm{g}^{-1}\right]$} \\
\hline & 0. day $^{\mathrm{a}}$ & 1st day & 5th day & 8th day & 14th day & 21th day & & $0-1$ st day ${ }^{\mathrm{a}}$ & $1-21$ th day $^{\mathrm{a}}$ & $0-21$ th day $^{\mathrm{a}}$ & bHydration $\left[\mathrm{g}_{\text {water }} / \mathrm{g}_{\mathrm{HS}}\right]$ \\
\hline ORIG & 355 & 269 & 258 & 252 & 251 & 251 & 106 & 86 & 18 & 104 & 29 \\
\hline ORIG_FM & 372 & 244 & 228 & 228 & 223 & 218 & 111 & 128 & 25 & 154 & 41 \\
\hline OX_P_1 & 366 & 220 & 208 & 201 & 199 & 192 & 109 & 145 & 29 & 174 & 48 \\
\hline OX_P_1_FM & 344 & 179 & 173 & 168 & 167 & 164 & 103 & 165 & 15 & 181 & 53 \\
\hline OX_P_3 & 361 & 214 & 211 & 203 & 197 & 197 & 108 & 147 & 17 & 164 & 45 \\
\hline OX_P_3_FM & 397 & 247 & 234 & 214 & 212 & 210 & 119 & 150 & 37 & 187 & 47 \\
\hline OX_N_1 & 320 & 195 & 191 & 189 & 189 & 189 & 96 & 125 & 6 & 131 & 41 \\
\hline OX_N_1_FM & 366 & 195 & 188 & 180 & 179 & 177 & 110 & 171 & 19 & 190 & 52 \\
\hline OX_N_5 & 373 & 218 & 213 & 200 & 200 & 200 & 112 & 155 & 18 & 174 & 47 \\
\hline OX_N_5_FM & 334 & 168 & 135 & 71 & 39 & 26 & 100 & 166 & 142 & 308 & 92 \\
\hline
\end{tabular}

a theoretical values, ${ }^{b}$ decrease of enthalpy after 21 days related to 0 day *100.

of cross-linked humic acids and a decrease in material compactness. The experiments dealing with the interaction of water with obtained humic acids indicated a decrease in moisture sorption capacity at low relative humidity and increase at higher relative humidity. This was attributed to the cross-link-induced increase in the distance between polar groups responsible for condensation of water in humic acids. The hydration study revealed that cross-link, together with an increase in molecular rigidity, caused unification of relaxation times distribution of water protons and facilitated the water penetration into the structure. It was showed that oxidation of parental humic acids followed by formaldehyde-based cross-linking induced a 3 fold increase in the water holding capacity of parental lignite humic acids. This is, however still below the capacity of synthetic soil hydrogel amendments.

The experiments clearly showed that chemistry of humic substances is connected also with their porosity, which is sometimes overlooked, especially in sorption experiments. In fact, the results showed that only a small change in chemical structure of humic acids can have a great influence on physical structure and thereby on physical properties. In other words, a small change of humic acids, representing soil organic matter, on microscopic scale can have large consequences in the macro world, which is still important to keep in mind in planning of environmental, agricultural and soil protection strategies.

\section{Acknowledgements}

The work was financially supported by the project "CEITEC - Central European Institute of Technology" (CZ.1.05/1.1.00/02.0068) from European Regional Development Fund.

\section{References}

Aquino, A., Tunega, D., Pasalic, H., Schaumann, G.E., Haberhauer, G., Gerzabek, M.H. Lischka, H., 2011. Molecular dynamics simulations of water molecule-bridges in polar domains of humic acids. Environ. Sci. Technol. 45 (19), 8411-8419.

Bakajova, B., Ilcin, M., Hola, O., Kucerik, J., 2011. Resistance of polyvinyl alcohol blends stabilized by sodium and ammonium salts of lignite humic acids against gammairradiation. J. Radioanal. Nucl. Chem. 287 (2), 449-458.

Bayer, J.V., Jaeger, F., Schaumann, G.E., 2010. Proton Nuclear magnetic resonance (NMR) relaxometry in soil science applications. Open Magn. Reson. J. 3. http://dx.doi.org/ 10.2174/1874769801003010015 (open access).

Borgia, G.C., Brown, R.J.S., Fantazzini, P., 1998. Uniform-penalty inversion of multiexponential decay data. J. Magn. Reson. 132, 65-77.

Borgia, G.C., Brown, R.J.S., Fantazzini, P., 2000. Uniform-penalty inversion ofmultiexponential decay data: II. Data spacing, T2 data, systematic data errors, and diagnostics. J. Magn. Reson. 147, 273-285.

Borisover, M., 2013. The effect of organic sorbates on water associated with environmentally important sorbents: estimating and the LFER analysis. Adsorption. http://dx.doi. org/10.1007/s10450-012-9446-7.

Borisover, M., Graber, E.R., 2004. Hydration of natural organic matter: effect on sorption of organic compounds by natural organic matter fractions vs natural organic matter source material. Environ. Sci. Technol. 38 (15), 4120-4129.

Brennan, J.K., Thomson, K.T., Gubbins, K.E., 2002. Adsorption of Water in Activated Carbons: Effects of Pore Blocking and Connectivity. Langmuir 18, 5438-5447.
Calemma, V., Iwanski, P., Rausa, R., Girardi, E., 1994. Changes in Coal Structure Accompanying the Formation of Regenerated Humic Acids During Air Oxidation. Fuel 73 (5), $700-707$.

Cimò, G., Kucerik, J., Berns, A.E., Schaumann, G.E., Alonzo, G., Conte, P., 2014. Effect of Heating Time and Temperature on the Chemical Characteristics of Biochar from Poultry Manure. J. Agric. Food Chem. 62, 1912-1918.

Conte, P., Alonzo, G., 2013. Environmental NMR: Fast-field-cycling Relaxometry. eMagRes 2, 389-398.

Conte, P., Piccolo, A., 1999. High Pressure Size Exclusion Chromatography (HPSEC) of humic substances. Molecular Sizes, Analytical Parameters, and Column Performance. Chemosphere 38, 517-528.

Conte, P.. Spaccini, R., Piccolo, A., 2006. Advanced CPMAS-C-13 NMR techniques for molecular characterization of size-separated fractions from a soil humic acid. Anal. Bioanal. Chem. 386 (2), 382-390.

Conte, P. Spaccini, R., Smejkalova, D., Nebbioso, A. Piccolo, A, 2007. Spectroscopic and conformational properties of size-fractions acid separated from a lignite humic. Chemosphere 69 (7), 1032-1039.

Conte, P., Loddo, V., De Pasquale, C., Marsala, V., Alonzo, G., Palmisano, L., 2013a. Nature of interactions at the interface of two water-saturated commercial TiO2 polymorphs. J. Phys. Chem. C 117, 5269-5273.

Conte, P., Marsala, V., De Pasquale, C., Bubici, S., Valagussa, M., Pozzi, A., Alonzo, G., 2013b. Nature of water-biochar interface interactions. GCB Bioenergy 5, 116-121.

Ctvrtnickova, A., Drastik, M., David, J., Kucerik, J., 2011. Surface and Solution Behavior of Surfactants Produced from Lignite Humic Acids. Fresenius Environ. Bull. 20 (7A), 1764-1771.

David, J., Smejkalova, D., Hudecova, S., Zmeskal, O., von Wandruszka, R., Gregor, T., Kucerik, J., 2014. Physico-chemical properties of regenerated humic substances correlated with their biostimulative activity. SpringerPlus 3, 156-171.

De Pasquale, C., Marsala, V., Berns, A., Valagussa, M., Pozzi, A., Alonzo, G., Conte, P., 2012. Fast field cycling NMR relaxometry characterization of biochars obtained from an industrial thermochemical process. J. Soils Sediments 12, 1211-2121.

Diehl, D., 2013. Soil water repellency: Dynamics of heterogeneous surfaces. Colloids Surf. A Physicochem. Eng. Aspects 432, 8-18.

Ferrante, G., Sykora, S., 2005. Technical aspects of fast field cycling. Adv. Inorg. Chem. - Incl. Bioinorg. Stud. 57 (57), 405-470.

Grasset, L., Ambles, A., 1998. Structure of humin and humic acid from an acid soil as revealed by phase transfer catalyzed hydrolysis. Org. Geochem. 29, 881-891.

Grasset, L., Guignard, C., Ambles, A., 2002. Free and esterified aliphatic carboxylic acids in humin and humic acids from a peat sample as revealed by pyrolysis with tetramethylammonium hydroxide or tetraethylammonium acetate. Org. Geochem. 33, 181-188.

Honek, J., Stanek, F., Honkova, K., Jelinek, J., 2009. Coal seams in the South Moravia Lignite Coalfield. Acta Montanist. Slovaca 14, 43-54.

Hurraß, J., Schaumann, G.E., 2007. Hydration kinetics of wettable and water repellent soil samples. Soil Sci. Soc. Am. J. 71 (2), 280-288.

Jaeger, F., Shchegolikhina, A., van As, H., Schaumann, G.E., 2010. Proton NMR Relaxometry as a Useful Tool to Evaluate Swelling Processes in Peat Soils. Open Magn. Reson. J. 3, $27-45$.

Jindo, K., Martim, S.A., Navarro, E.C., Perez-Alfocea, F., Hernandez, T., Garcia, C., Aguiar, N. O., Canellas, L.P., 2012. Root growth promotion by humic acids from composted and non-composted urban organic wastes. Plant Soil 353 (1-2), 209-220.

Kefi, S., Rietkerk, M., Alados, C.L., Pueyo, Y., Papanastasis, V.P., ElAich, A., de Ruiter, P.C., 2007. Spatial vegetation patterns and imminent desertification in Mediterranean arid ecosystems. Nature 449 (7159), 213-U215.

Kimmich, R., Anoardo, E., 2004. Field-cycling NMR relaxometry. Prog. Nucl. Magn. Reson. Spectrosc. 44 (3-4), 257-320.

Knicker, H., 2010. "Black nitrogen" - an important fraction in determining the recalcitrance of charcoal. Org. Geochem. 41 (9), 947-950.

Knicker, H., Hilscher, A., de la Rosa, J.M., Gonzalez-Perez, J.A., Gonzalez-Vila, F.J., 2013. Modification of biomarkers in pyrogenic organic matter during the initial phase of charcoal biodegradation in soils. Geoderma 197, 43-50.

Kovalenko, A.N., Ilyukhina, E.A., Perminova, I.V., Ponomarenko, S.A., Hertkorn, N., Petrosyan, V.S., 2006. Synthesis of cross-linked humic substances using phenolformaldehyde polycondensation. In: Frimmel, F.H., Abbt-Braun, G. (Eds.), Proceedings of the 13th Meeting of the International Humic Substances Society. IHSS, Karslruhe, pp. 273-275. 
Kucerik, J., Pekar, M., Klucakova, M., 2003. South-Moravian lignite - potential source of humic substances. Pet. Coal 45, 58-62.

Kucerik, J., Kovar, J., Pekar, M., 2004. Thermoanalytical investigation of lignite humic acids fractions. J. Therm. Anal. Calorim. 76 (1), 55-65.

Kucerik, J., Kovar, J., Pekar, M., Simon, P., 2005. Evaluation of oxidation stability of lignite humic substances by DSC induction period measurement. Naturwissenschaften 92 (7), 336-340.

Kucerik, J., Smejkalova, D., Cechlovska, H., Pekar, M., 2007. New insights into aggregation and conformational behaviour of humic substances: Application of high resolution ultrasonic spectroscopy. Org. Geochem. 38 (12), 2098-2110.

Kučerík, J., Cihlář, Z., Vlčková, Z., Drastík, M., 2008. Regenerated Humic Acids Obtained by the Air Oxidation of South Moravian Lignite. Part. 1. Production and Characterization. Pet. Coal 50 (3), 49-55.

Kucerik, J., Bursakova, P., Prusová, A., Grebikova, L., Schaumann, G.E., 2012. Hydration of humic and fulvic acids studied by DSC. J. Therm. Anal. Calorim. 110, 451-459.

Kunhi Mouvenchery, Y., Jaeger, A., Aquino, A.J.A., Tunega, D., Diehl, D., Bertmer, M., Schaumann, G.E., 2013. Restructuring of a peat in interaction with multivalent cations: Effect of cation type and aging time. PLoS One 8 (6), e65359.

Lehmann, J., Joseph, S., 2009. Biochar for environmental management: an introduction. In: Lehamn, J., Joseph, S. (Eds.), Biochar for environmental management: science and technology. Earthscan, London, pp. 1-13.

Liu, J.-C., Monson, P.A., 2005. Does Water Condense in Carbon Pores? Langmuir 21, 10219-10225.

Madari, B.E., Maia, C.M.B.d.F., Novotny, E.H., 2012. Context and importance of biochar research, 47. Pesquisa Agropecuária Brasileira, pp. 1-2.

Marova, I., Kucerik, J., Duronova, K., Mikulcova, A., Vlckova, Z., 2011. Antimutagenic and/or genotoxic effects of processed humic acids as tested upon S. cerevisiae D7. Environ. Chem. Lett. 9 (2), 229-233.

McCallum, C.L., Bandosz, T.J., McGrother, S.C., Muller, E.A., Gubbins, K.E., 1999. A molecular model for adsorption of water on activated carbon: Comparison of simulation and experiment. Langmuir 15 (2), 533-544.

Mlcoch, T., Kucerik, J., 2013. Hydration and drying of various polysaccharides studied using DSC. J. Therm. Anal. Calorim. 113 (3), 1177-1185.

Nasir, S., 2011. Industrial Applications of Lignite Humic Acid: Structure, Properties and Consequence for Utilization. LAP LAMBERT, Academic Publishing GmbH \& Co., Saarbrucken, Germany.

Nasir, S., Sarfaraz, T.B., Parveen, R., Aleem, A., Khan, K.M., 2011a. Synthesis Colorfastness Evaluation and Utilization of Humic Acid Derived Dyes and Pigment. J. Chil. Chem. Soc. 56, 559-565.

Nasir, S., Sarfaraz, T.B., Verheyen, T.V., Chaffee, A.L., 2011b. Structural Elucidation of Humic Acid Extracted from Pakistani Lignite Using Spectroscopic and Thermal Degradative Techniques. Fuel Process. Technol. J. 92, 983-991.
Perminova, I.V., Hatfield, K., 2005. Remediation Chemistry of Humic Substances: Theory and Implications for Technology. In: P. I.V., H. K., H. N. (Eds.), Use of humic substances to remediate polluted environments: from theory to practice. NATO Science Series: IV: Earth and Environmental Sciences, vol. 52. Springer, Dordrecht, The Netherlands, pp. 3-36.

Perminova, I.V., Kovalenko, A.N., Schmitt-Kopplin, P., Hatfield, K., Hertkorn, N., Belyaeva, E.Y., Petrosyan, V.S., 2005. Design of quinonoid-enriched humic materials with enhanced redox properties. Environ. Sci. Technol. 39 (21), 8518-8524.

Pignatello, J.J., 2012 Dynamic interactions of natural organic matter and organic compounds. J. Soils Sediments 12 (8), 1241-1256.

Prusova, A., Smejkalova, D., Chytil, M., Velebny, V., Kucerik, J., 2010. An alternative DSC approach to study hydration of hyaluronan. Carbohydr. Polym. 82 (2), 498-503.

Prusova, A., Vergeldt, F.J., Kucerik, J., 2013. Influence of water content and drying on the physical structure of native hyaluronan. Carbohydr. Polym. 95, 515-521.

Ryabova, I.N., Mustafina, G.A., 2003. Modification of coal humic acids with formaldehyde. Russ. J. Appl. Chem. 76, 269-271.

Schaumann, G.E., Bertmer, M., 2008. Do water molecules bridge soil organic matter molecule segments? Eur. J. Soil Sci. 59 (3), 423-429.

Schaumann, G.E., LeBoeuf, E.J., 2005. Glass transitions in peat - their relevance and the impact of water. Environ. Sci. Technol. 39 (3), 800-806.

Schaumann, G.E., Hobley, E., Hurraß, J., Rotard, W., 2005. H-NMR Relaxometry to monitor wetting and swelling kinetics in high organic matter soils. Plant Soil 275 (1-2), 1-20.

Schneckenburger, T., Lattao, C.V., Pignatello, J.J., Schaumann, G.E., Thiele-Bruhn, S., Cao, X Mao, J., 2012. Preparation and characterization of humic acid cross-linked with organic bridging groups. Org. Geochem. 47 (2012), 132-138.

Simpson, A.J., 2002. Determining the molecular weight, aggregation, structures and interactions of natural organic matter using diffusion ordered spectroscopy. Magn. Reson. Chem. 40, S72-S82.

Simpson, M.J., Hatcher, P.G., 2004. Determination of black carbon in natural organic matter by chemical oxidation and solid-state C-13 Nuclear Magnetic Resonance spectroscopy. Org. Geochem. 35 (8), 923-935.

Stevenson, F.J., 1994. Humus Chemistry: Genesis, Composition, Reactions. Wiley, New York.

Sutton, R., Sposito, G., 2005. Molecular structure in soil humic substances: The new view. Environ. Sci. Technol. 39 (23), 9009-9015.

Tatzber, M., Stemmer, M., Spiegel, H., Katzlberger, C., Haberhauer, G., Mentler, A., Gerzabek, M.H., 2007. FTIR-spectroscopic characterization of humic acids and humin fractions obtained by advanced $\mathrm{NaOH}, \mathrm{Na} 4 \mathrm{P} 2 \mathrm{O} 7$ and $\mathrm{Na} 2 \mathrm{CO} 3$ extraction procedures. J. Plant Nutr. Soil Sci. 170, 522-529.

von Wandruszka, R., 2000. Humic acids: Their detergent qualities and potential uses in pollution remediation. Geochem. Trans. 1, 10-16.

Wu, C.-S., 2004. Handbook of size exclusion chromatography and relted techniques, 2nd ed. Chromatographic science series, 91. Marcel Dekker. 